\title{
Quality of spirometry tests and pulmonary function changes among industrial company workers in Iran: a two-year before-and-after study following an intensive training intervention
}

\section{Seyed Mohammad Seyedmehdi', *Mirsaeed Attarchi' ${ }^{2}$ Taraneh Yazdanparast ${ }^{1}$, Maziar Moradi Lakeh ${ }^{3}$}

\author{
Chronic Respiratory Disease Research Center (CRDRC), Air Pollution, Health and Occupational Diseases Research Unit, National Research \\ Institute of Tubeclosis and Lung Disease (NRITLD), Shahid Beheshti University of Medical Sciences, Tehran, Iran \\ ${ }^{2}$ Occupational Medicine Department, School of Medicine, Tehran University of Medical Sciences, Tehran, Iran \\ ${ }^{3}$ Community Medicine Department, School of Medicine, Tehran University of Medical Sciences, Tehran, Iran
}

Originally received 28th July 2012; resubmitted 28th October; revised 24th December 2012; accepted 14th January 2013; online 25th February 2013

\begin{abstract}
Background: Quality improvement, standardisation of spirometry testing, and interpretation of results are critically important in the occupational setting.

Aims: To determine the quality of spirometry tests and pulmonary function changes in two consecutive years among the personnel of an industrial company.

Methods: This study was performed in an oil refinery in Iran in 2011. Data on 1,004 male personnel were evaluated before and after a training course conducted according to the National Institute for Occupational Safety and Health guidelines. American Thoracic Society/European Respiratory Society guidelines were used for assessment of the acceptability and repeatability criteria.

Results: The most common error in the first year of evaluation was forced vital capacity $>6$ seconds or a 1 second plateau. Acceptability and proper interpretation significantly improved after the course $(p<0.05)$, but repeatability did not change significantly $(p>0.05)$.

Conclusions: The results of this study show that the validity and quality of spirometric tests conducted in the studied company in Iran were unacceptable, but these improved significantly after the training intervention. The study demonstrated the lack of a systematic guideline for conducting spirometry and interpreting the results in the occupational setting in Iran, and emphasises the need for a nationwide programme to improve the quality of spirometry tests in this setting.

(C) 2013 Primary Care Respiratory Society UK. All rights reserved.

S Mohammad Seyedmehdi et al. Prim Care Respir J 2013; 22(1): 86-91

http://dx.doi.org/10.4104/pcrj.2013.00018
\end{abstract}

Keywords spirometry test, pulmonary function changes, industrial company, training course

See linked editorial by Enright \& Schermer on pg 15

\section{Introduction}

Respiratory diseases are among the most common causes of mortality and morbidity in the occupational setting. The National Institute for Occupational Safety and Health (NIOSH) estimates that deaths from work-related respiratory diseases account for about $70 \%$ of all deaths from occupational disease. ${ }^{1}$ Approximately $10-15 \%$ of cases of adult asthma may be attributed to occupation, and cohort studies have shown that $20 \%$ or more of working people with asthma can have exacerbations of their asthma due to work-related exposures and conditions. ${ }^{2}$ Also, $15 \%$ of cases of chronic obstructive pulmonary disease (COPD) may be due to occupational exposures, ${ }^{3}$ and less prevalent lung diseases such as bronchiolitis obliterans have been reported in cases with occupational exposures. ${ }^{4}$ Additionally, it has been shown that pulmonary function testing is an important predictor of mortality. ${ }^{5,6}$

In occupations believed to be associated with the risk of

\footnotetext{
* Corresponding author:Dr Mirsaeed Attarchi, Occupational Medicine Department, School of Medicine, Tehran University of Medical Sciences, 1648665363 Tehran, Iran. Tel/Fax: +9802166551204 E-mail: msattarchi@yahoo.com
} 
pulmonary diseases, periodic spirometry is usually conducted in workers to monitor their lung function and prevent work-related respiratory conditions. Workplace monitoring through conduction of spirometry tests of forced expiratory volume in one second (FEV 1 ) and forced vital capacity (FVC) is widely performed for early (preclinical) recognition of both obstructive and restrictive lung diseases ${ }^{7,8}$ Other indications for periodic spirometry in occupational settings include assessment of fitness to wear respirators and maintaining workers' general health..$^{9-11}$

Quality improvement, standardisation of spirometry testing, and interpretation of results are critically important in the occupational setting. More than 150 years have passed since the first spirometry test, yet it is still performed with suboptimal quality leading to false positive and false negative results. ${ }^{12}$ Almost all currently available spirometers meet the American Thoracic Society (ATS) criteria for accuracy and repeatability ${ }^{12}$ but, in clinical settings, technicians and general practitioners (GPs) do not usually use these devices properly. Spirometry tests are technically demanding, and selection of the device and its calibration prior to testing are especially important in performing a proper test. Although spirometry is often described as a simple screening test, it has a more important role in determining pulmonary performance. In generally healthy worker populations, making a diagnosis based on longitudinal data (periodic spirometry) may be more beneficial than a single abnormal spirometry test. ${ }^{10-13}$ High quality spirometry depends on both participants and technicians because effort plays a central role in the flow-volume curve. ${ }^{14,15}$ Previous researchers have recommended criteria for evaluating spirometry quality over time. ${ }^{16}$ Nevertheless, data are limited on the accuracy of spirometric measurements and acceptable precision of longitudinal data for spirometry monitoring. ${ }^{17}$ In a previous study, only $33.1 \%$ of spirometry tests performed by trained primary care providers and $12.5 \%$ of those performed by control group participants achieved the requirement of a minimum of two acceptable spirometry manoeuvres. ${ }^{18}$ Poor quality of spirometry in the primary care setting is an international concern and can lead to secondary care referrals. ${ }^{19}$ It has been shown that an educational intervention in the primary care setting to minimise the risk of poor quality spirometry tests (due to poor technique) can reduce unnecessary secondary care referrals. ${ }^{20}$

Every day we encounter several workers who are referred to our clinic for further evaluation because of spirometric abnormalities. Most of these spirometric measurements have technical errors. There is no approved training programme for technicians and GPS who want to perform spirometry or interpret the results. Apart from occupational medicine specialists, GPs who have participated in occupational medicine courses are legally eligible to supervise spirometry tests and to interpret the results in the occupational setting. Performance of spirometry tests and interpretation of the results are part of these training courses. However, based on our experience, complete and proper training of GPs is not possible in these training courses. Although spirometry tests are commonly performed in occupational settings in our country, they have not been sufficiently evaluated.

This study sought to determine the quality of spirometry tests and changes in periodic pulmonary function testing in two consecutive years among workers at an industrial company in Iran.

\section{Methods}

\section{Study design and subjects}

The study was performed in an oil refinery in Iran in 2011. Data on 1,004 male workers were evaluated. The first phase of the study was started in June 2010. All spirometry tests and interpretations done by technicians and GPs at the refinery were checked by two independent occupational medicine specialists who were experienced in spirometry. In this oil refinery, two technicians perform the spirometry tests and three GPs interpret the results. These staff were not changed or replaced during these two consecutive years. All understudy subjects (technicians and GPs) had a minimum of seven years of work experience.

The basic inclusion criteria for the study were at least one year of work experience in the oil refinery and possession of a complete data profile for the year before the intervention. All co-workers participated voluntarily in the study and provided written informed consent. The study was approved by the Ethics Committee of the National Research Institute of Tuberculosis and Lung Diseases (NRITLD).

\section{Pulmonary function test and training course}

American Thoracic Society/European Respiratory Society (ATS/ERS) guidelines were used for assessment of acceptability and repeatability criteria. These guidelines include exhaling with maximum effort, aiming to achieve at least three acceptable and two reproducible curves. ${ }^{15}$

Spirometry tests were considered 'acceptable' if they were free from artifacts (cough during the first second of exhalation, glottis closure that affected the measurement, early termination or cut-off, less than maximal effort during the test, leak, obstructed mouthpiece), had good starts (extrapolated volume $<5 \%$ of FVC or $0.15 \mathrm{~L}$, whichever was greater), and had satisfactory exhalation (duration of $\geq 6$ seconds or a 1 second plateau in the volume-time curve or if the subject could not or should not continue to exhale).

After three acceptable spirometry tests, repeatability criteria were considered as the two largest FVC values within $150 \mathrm{ml}$ of each other and the two largest $\mathrm{FEV}_{1}$ values within $150 \mathrm{ml}$ of each other. ${ }^{14}$

The intervention, which consisted of technician training according to the $\mathrm{NIOSH}$-approved spirometry training course ${ }^{21}$ and monitoring of the quality and precision of spirometry tests and their interpretations, was then initiated. A total of 1,004 pre- and postintervention spirometry tests were evaluated. The training course consisted of eight hours of formal lectures, eight hours of practical education for the two technicians and four hours of practical education for the three GPs, followed by two hours of evaluation of the participants' spirometry skills with both written and practical examinations. The course content included the following:

- Basic physiology of the FVC manoeuvre and the determinants of airflow limitation with emphasis on its relation to repeatability of results.

- Knowledge about the device and its requirements, calibration check procedures, how to find sources of errors, and their 
Table 1. Descriptive statistics of spirometry tests that had acceptability and repeatability criteria before and after the course ( $N=1,004$ tests)

\begin{tabular}{|c|c|c|c|}
\hline & $\begin{array}{l}\text { Before the course } \\
\mathrm{N}(\%)\end{array}$ & $\begin{array}{l}\text { After the course } \\
\mathrm{N}(\%)\end{array}$ & $\mathrm{p}$ Value \\
\hline \multicolumn{4}{|l|}{ Acceptability criteria } \\
\hline $\begin{array}{l}\text { Satisfactory exhalation (duration of } 6 \text { seconds or } 1 \text { second } \\
\text { plateau in the volume-time curve) }\end{array}$ & $298(29.6)$ & $922(91.8)$ & $<0.05$ \\
\hline $\begin{array}{l}\text { Good starts (extrapolated volume }<5 \% \text { of FVC or } 0.15 \mathrm{~L} \text {, } \\
\text { whichever was greater) }\end{array}$ & $635(63.2)$ & $967(96.3)$ & $<0.05$ \\
\hline Spirograms free from artifacts* & $794(79.1)$ & $818(81.5)$ & $<0.05$ \\
\hline Repeatability criteria & $958(98.1)$ & 999 (99.5) & $>0.05$ \\
\hline Repeatability of $F E V_{1}(\mathrm{~mL})^{+}$ & 141 & 138 & $>0.05$ \\
\hline Repeatability of FVC $(\mathrm{mL})^{\dagger}$ & 143 & 135 & $>0.05$ \\
\hline
\end{tabular}

correction with the results.

- Performance testing, subject coaching, recognition of improperly performed manoeuvres, and corrective actions.

- Quality of results.

- Actual use of the device under supervised conditions.

- Measurement of tracings and calculation of results.

Additionally, a pamphlet on spirometry errors with figures and an instruction form containing indications and contraindications of spirometry were administered to course participants. A refresher training course was held for the same participants six months later. This course was conducted according to the $\mathrm{NIOSH}$-approved refresher training course guidelines. ${ }^{21}$ The technicians' refresher training course focused primarily on enhancing their skills and coaching them to improve test quality. After the refresher course, another examination similar to the previous one was performed.

These training courses were scheduled between two periodic examinations of the refinery personnel. After completion of these training courses, the participating GPs and technicians fulfilled the criteria for pulmonary function testing and interpretation of results. All understudy subjects underwent closed-circuit spirometry by a calibrated portable spirometer (Spirolab III, MIR Co., Italy). The Spirolab III spirometer displays quality grades and offers an automated interpretation; however, this device does not display a specific error message for each error. In this study, the quality of device messages was not considered as an index for rejecting or accepting the spirometry test. All spirometry tests were reviewed by two occupational medicine specialists based on ATS/ERS criteria, and data from the first and second years were compared. FEV $1 / F V C$ $<0.70$ (obstruction) and FVC $<80 \%$ predicted (restriction) were used to define abnormal spirometry results.

Before the initiation of the main study, a checklist of errors that could make the test unacceptable or unrepeatable was prepared based on ATS/ERS criteria. One hundred spirometry tests were then reviewed by both reviewers and interpersonal variability was assessed (kappa coefficient 95\%). These tests were excluded from the main study. The checklist was completed for all spirometry tests.
Two technicians, three GPs, and 1,004 workers entered the study. In order for the data to be complete and interpretable, participants had to submit three spirometry curves per testing session. The two reviewers were present in the setting two days a week. Thus, post-training continuous monitoring by the technicians was not available. However, the technicians and GPs had access to the reviewers in their off days.

\section{Statistical analysis}

Data were analysed using descriptive and analytical statistical methods and SPSS version 11.0 software. To compare quantitative variables, the paired t-test was applied and the McNemar test was used for qualitative variables; $p<0.05$ was considered statistically significant.

\section{Results}

A total of 1,004 spirometry tests were evaluated. At the start of the study the mean (SD) age of the workers was 37.6 (6.3) years (range 20-62) and all were male. The mean (SD) body mass index (BMI) was $25.5(3.38) \mathrm{kg} / \mathrm{m}^{2}$ (range 16.9-35.8) and mean (SD) work experience was 11.44 (4.31) years (range 1-25). The mean (SD) weight and height of participants was 76.13 (11.58) kg (range 45-107) and $172.6(6.85) \mathrm{cm}$ (range 152-197), respectively. A total of 264 participants were smokers (26.3\%) and mean (SD) cigarette consumption in smokers was 8.36 (5.25) pack/years. Mean cigarette consumption and shift work did not change significantly in the two consecutive years $(p>0.1)$, and the mean weight of participants did not change significantly during the two-year follow-up period ( $p>0.05)$. The following outcomes were evaluated for assessing the impact of the interventions: percentage of spirometry tests fulfilling the ATS/ERS recommendations; decline in most frequent spirometry test and interpretation errors; and the percentage of improvement in spirometric values ( $\mathrm{FEV}_{1}, \mathrm{FVC}, \mathrm{FEV}_{1} \%$ ).

Table 1 shows descriptive statistics of the spirometry tests before and after the course. The most common error in year 1 was FVC $>6$ seconds or a 1 second plateau. Table 2 shows the changes in mean spirometric values. The mean of all spirometric values in year 2 increased significantly compared with the same values in year 1 
Table 2. Spirometry test values of participants in study years 1 and 2

\begin{tabular}{l|lll|llll} 
& Year 1 & & Year 2 & & $p$ Value \\
\hline & Mean & 5th percentile & 95th percentile & Mean & 5th percentile & 95th percentile & \\
\hline FEV $_{1}, \mathrm{~L}(\%)$ & $3.04(87.24)$ & 1.38 & 4.34 & $3.22(94.13)$ & 1.45 & 4.71 & $<0.001$ \\
\hline FVC, L (\%) & $4.20(88.20)$ & 2.01 & 5.46 & $4.36(92.71)$ & 2.16 & 5.66 & $<0.001$ \\
\hline FEV $/$ FVC (\%) & 87.19 & 71.44 & 90.01 & 90.32 & 73.67 & 91.7 & $<0.001$ \\
\hline
\end{tabular}

$\mathrm{FEV}_{1}=$ forced expiratory volume in one second, $\mathrm{FVC}=$ forced vital capacity.

Table 3. General practitioners' interpretations and rate of correct interpretation before and after the course ( $N=1,004$ tests)

\begin{tabular}{|c|c|c|c|c|c|}
\hline & & Normal & Obstructive & Restrictive & Mixed \\
\hline \multirow[t]{3}{*}{ Interpretation of spirometry test } & Before the course, $\mathrm{N}(\%)$ & $863(86.0)$ & $81(8.1)$ & $35(3.5)$ & $25(2.5)$ \\
\hline & After the course, N (\%) & $885(88.1)$ & 79 (7.9) & $16(1.6)$ & $24(2.4)$ \\
\hline & $\mathrm{p}$ Value & $>0.05$ & $>0.05$ & $<0.05$ & $>0.05$ \\
\hline \multirow{3}{*}{$\begin{array}{l}\text { Rate of correct interpretation of } \\
\text { spirometry test }\end{array}$} & Before the course (\%) & $51 \%$ & $59 \%$ & $42 \%$ & $62 \%$ \\
\hline & After the course (\%) & $91 \%$ & $90 \%$ & $99 \%$ & $98 \%$ \\
\hline & p Value & $<0.05$ & $<0.05$ & $<0.001$ & $<0.05$ \\
\hline
\end{tabular}

Table 4. Association between good quality of spirometry tests and study variables using logistic regression analysis (2008 tests)

\begin{tabular}{llll} 
GPs' and technicians' variables & $\begin{array}{l}\text { Adjusted } \\
\text { OR }\end{array}$ & $\begin{array}{l}95 \% \\
\text { Cl }\end{array}$ & $\begin{array}{l}\mathrm{p} \\
\text { Value }\end{array}$ \\
\hline First technician $(n=1,199$ tests) & 1.000 & - & - \\
Second technician $(n=809$ tests) & 0.720 & 0.385 to 1.347 & 0.304 \\
\hline First GP $(n=702$ tests) & 1.000 & - & - \\
Second GP $(n=584$ tests) & 0.967 & 0.738 to 1.268 & 0.809 \\
Third GP ( $n=722$ tests) & 1.277 & 0.674 to 2.421 & 0.454 \\
\hline Training course & & & \\
$\quad$ Before ( $n=1,004$ tests) & 1.000 & - & - \\
After ( $n=1,004$ tests) & 13.651 & 10.916 to 17.071 & $<0.001$ \\
\hline
\end{tabular}

Workers' variables

Age (years)

$\leq 38$ ( $n=944$ tests)

$>38$ ( $n=1,064$ tests)

Work duration (years)

$\leq 12$ ( $n=964$ tests)

$>12$ ( $n=1,044$ tests)

13.651

0.916 to $17.071<0.001$

Cigarette smoking

No ( $n=1,480$ tests)

Yes ( $n=528$ tests)

1.000

$1.154 \quad 0.907$ to $1.469 \quad 0.244$

Shift work

No ( $n=644$ tests)

Yes ( $n=1364$ tests)

1.000

$\begin{array}{lll}0.880 & 0.691 \text { to } 1.120 \quad 0.297\end{array}$

Educational levels

Guidance and high school $\quad 1.000$

( $n=270$ tests)

$\begin{array}{llll}\text { High school graduate } & 1.014 & 0.619 \text { to } 1.468 & 0.827\end{array}$

( $n=1,060$ tests)

Associate degree*

1.057

0.635 to 1.332

0.658

( $n=414$ tests)

$1.156 \quad 0.757$ to $1.764 \quad 0.502$

$\geq \mathrm{BSC}^{\dagger}$ ( $n=264$ tests)

scol graduate and Bachelor of Science.

*Educational level betwe

tBachelor of Science $(p<0.001)$.

In this study, GPs had errors in terms of repeatability and acceptability of the tests and also wrong interpretation. A total of 149 tests $(14.8 \%)$ met all the acceptability criteria in year 1 , and this rate reached 706 tests $(70.3 \%)$ in year $2(p<0.05)$. The rate of correct interpretations by physicians also increased from 531 (52.9\%) in year 1 to $910(90.6 \%)$ in year $2(p<0.05)$. However, no significant differences were detected in repeatability of the tests between year 1 (958 tests, 98.1\%) and year 2 (999 tests, 99.5\%). Table 3 shows the details of incorrect interpretations. The only significant reduction occurred in restrictive interpretation $(p<0.05$, Table 3 ). We also evaluated spirometry tests that were conducted and interpreted accurately. The rate of correct spirometry tests increased significantly in the year after the workshop $(p<0.05)$. In order to evaluate other factors that may affect the educational programme results, data from the first year were compared with those of the previous year. No significant difference was found in the main observed outcomes (acceptability and repeatability percentage, $\mathrm{FEV}_{1}, \mathrm{FVC}$, and $\mathrm{FEV}_{1} / \mathrm{FVC}$ ).

Finally, logistic regression analysis was used for more precise evaluation of the relationship between good quality spirometry testing (i.e. spirometry tests with acceptability and repeatability criteria in addition to correct interpretation) and the training course. The analysis showed that, even after adjusting confounding factors for technicians, GPs, and workers, there was a significant relationship between a good quality spirometry test and the training course $(p<0.001$, Table 4).

\section{Discussion}

\section{Main findings}

In this study we evaluated the quality of spirometry tests and their interpretation in two years in an industrial company. In high-risk occupations, it is recommended that precise spirometric test results especially longitudinal data - are obtained periodically in order to 
prevent respiratory conditions among personnel. ${ }^{8,22}$ To achieve the maximum potential of spirometry for detecting respiratory conditions among the workforce, it is necessary to reach an acceptable test quality. This study is the first to evaluate the quality of periodic spirometry tests and its improvement in the occupational setting in Iran. No systematic training or retraining programmes regarding the conduction and interpretation of periodic spirometry tests are available in Iran. In this study only $14.8 \%$ of spirometry tests met the ATS acceptability criteria. Insufficient education and training, or not paying enough attention by technicians and GPs, are among the possible reasons. The present study results demonstrated that, after educational workshops, the rate of acceptable spirometry tests increased from $14.8 \%$ to $70.3 \%$. These findings confirm that proper training and supervision can improve test results. We cannot define the exact role of each of these factors, but training may play a more prominent role than improved supervision.

\section{Interpretation of findings in relation to previously published work}

The Lung Health Study showed that only $2.1 \%$ of participants were unable to produce three acceptable FVC manoeuvres. ${ }^{23}$ Our results showed the necessity of training and retraining workshops in the occupational setting in Iran. Pre- and post-workshop written assessments also showed significant improvement in participants' performance. Eaton et al. ${ }^{18}$ demonstrated that, due to the possibility of forgetting some information, continuous training is necessary for preserving the quality of spirometry tests. We therefore provided participants with a written instruction manual and attached a poster to the wall to reduce the risk of forgetting the criteria. Additionally, a retraining workshop based on NIOSH standards was scheduled to be held six months after the first workshop.

In this study, $52.9 \%$ of interpretations were correct before the workshop. This finding was similar to that in the study by Eaton et al. ${ }^{18}$ After the training workshop the rate of correct interpretations increased up to $90.6 \%$ (Table 3 ). This finding clearly shows the need for training in both conduction of spirometry testing and interpretation of the results. High rates of misclassification (false positives and false negatives) in the occupational setting can lead to unacceptable results. False positives can result in unnecessary secondary care referrals, wasting the time of the workforce and imposing unnecessary costs. On the other hand, false negatives can cause failure in the early diagnosis of occupational lung diseases.

This study showed that, after the course, mean $\mathrm{FEV}_{1}$ values improved more than mean FVC values, suggesting that the improved technique yielded deeper inhalations. $\mathrm{FEV}_{1}$ increases by taking deeper breaths prior to forced exhalations while FVC increases by taking deeper breaths and longer exhalation times (reaching a volume-time plateau).

Our results showed that the prevalence of restriction was low (1.6\% even after the course) despite the workplace exposures and the high prevalence of obesity among the workers.

An inappropriate reference equation for the lower limit of FVC may explain this finding. Another possibility is that smoking and occupational exposures may have resulted in manifestation of an obstructive pattern. The healthy worker effect may also explain a portion of this finding. Additionally, since the 5th percentile lower limit of normal (LLN) was not available for our population, we used $\mathrm{FEV}_{1} / \mathrm{FVC}<0.70$ and FVC $<80 \%$ predicted to define abnormal spirometry results. Miller et al. showed that using fixed thresholds (instead of 5 th percentile LLN) can result in $>20 \%$ misdiagnosis in COPD patients. ${ }^{24}$

\section{Strengths and limitations of the study}

This study has some limitations. First, a small group of technicians and GPs participated in the study and we cannot claim that they are truly representative of this group of healthcare workers in society. Second, other studies have shown that, in relatively healthy working populations, the level of data precision can reach $4 \%$ or less. ${ }^{9}$ Also, in the BOLD study performed in 14 countries, $10 \%$ of participants failed to perform a proper spirometry test that met the ATS/ERS criteria. ${ }^{25}$ In our study, data precision after the training courses was lower. Other factors such as the aptitude of the spirometry tester may affect our results and can be the subject of further investigations.

One strength of this study is that it is the first study in this subject group in Iran. The study evaluated the critical role of education in improving the quality of spirometry tests. Other approaches, such as paying only for good quality spirometry tests, may be more effective. Further research in this respect is required to obtain insight on this issue.

\section{Conclusions}

The results of this study show that the validity and quality of spirometric tests conducted in an industrial company in Iran were unacceptable, but they improved significantly following the NOSHapproved training intervention. The study demonstrated the lack of a systematic guideline for conducting spirometry tests and interpreting the results in an occupational setting in Iran, and emphasised the need for a nationwide programme to improve the quality of spirometry tests in the occupational setting.

\section{Handling editor David Bellamy Statistical review Gopal Netuveli}

Conflicts of interest The authors declare that they have no conflicts of interest in relation to this article.

Contributorship MSA had the original idea. MSA and SMS and TY contributed to and approved the manuscript. MML contributed to the statistical analysis.

Funding This study was sponsored by the National Research Institute of Tuberculosis and Lung Diseases (NRITLD), Iran.

\section{References}

1. Utell M, Balmes J, Blanc P, et al. Respiratory Diseases Research at NIOSH, National Academy of Sciences, 2008. Available from: http://dels.nas.edu/best.

2. Tarlo S, Cullinan $P$, Nemery B. Occupational and environmental lung diseases. John Wiley \& Sons, 2010, p 2. http://dx.doi.org/10.1002/9780470710425

3. Fishwick D, Naylor S. COPD and the workplace. Is it really possible to detect early cases? Occup Med 2007;57:82-4. http://dx.doi.org/10.1093/occmed/kql138

4. Kim TJ, Materna BL, Prudhomme JC, et al. Industry-wide medical surveillance of California flavor manufacturing workers: cross-sectional results. Am J Ind Med 2010; 53(9):857-65.

5. Sircar K, Hnizdo E, Petsonk E, Attfield M. Decline in lung function and mortality: implications for medical monitoring. Occup Environ Med 2007;64:461-6. http://dx.doi.org/10.1136/oem.2006.031419

6. Young RP, Hopkins R, Eaton TE. Forced expiratory volume in one second: not just a lung function test but a marker of premature death from all causes. Eur Respir $J$ 
2007;30:616-22. http://dx.doi.org/10.1183/09031936.00021707

7. Vandevoorde J, Verbanck S, Schuermans D, Kartounian J, Vincken W. FEV1/FEV6 and FEV6 as an Alternative for FEV1/FVC and FVC in the Spirometric Detection of Airway Obstruction and Restriction. Chest 2005;127:1560-64. http://dx.doi.org/ 10.1378/chest.127.5.1560

8. Townsend MC. Evaluating pulmonary function change over time in the occupational setting. ACOEM evidence-based statement. J Occup Environ Med 2005;47:1307-16. http://dx.doi.org/10.1097/01.jom.0000188332.10217.4b

9. Wagner GR. Screening and Surveillance of Workers Exposed to Mineral Dust. Geneva: World Health Organization, 1996.

10. Townsend M, Occupational and Environmental Lung Disorders Committee. Spirometry in occupational health setting-2011 update. J Occup Environ Med 2011;53:569-84. http://dx.doi.org/10.1097/JOM.0b013e31821aa964

11. Hnizdo E, Berry A, Hakobyan A, Beeckman-Wagner LA, Catlett L. Worksite wellness program for respiratory disease prevention in heavy construction workers. J Occup Environ Med 2011;53:274-81. http://dx.doi.org/10.1097/JOM.0b013e31820b0ab1

12. Enright PL. How to make sure your spirometry tests are of good quality. Respir Care 2003;48:773-6.

13. Hankinson JL, Wagner GR. Medical screening using periodic spirometry for detection of chronic lung disease. Occup Med 1993;8:353-61.

14. Miller MR, Hankinson J, Brusasco V, et al. Standardisation of spirometry. Eur Respir J 2005;26:319-38. http://dx.doi.org/10.1183/09031936.05.00034805

15. Upton MN, Ferrell C, Bidwell C, et al. Improving the quality of spirometry in an epidemiological study: the Renfrew-Paisley (Midspan) family study. Public Health 2000;114:353-60.

16. Enright PL, Skloot GS, Cox-Ganser JM, Udasin IG, Herbert R. Quality of spirometry performed by 13,599 participants in the World Trade Center worker and volunteer medical screening program. Respir Care 2010;55:303-09.

17. Hnizdo E, Hakobyan A, Fleming J, Beeckman-Wagner L. Periodic spirometry in occupational setting: improving quality, accuracy, and precision. J Occup Environ Med 2011;53:1205-09. http://dx.doi.org/10.1097/JOM.0b013e31823078b8

18. Eaton T, Withy S, Garrett JE, Mercer J, Whitlock RM, Rea HH. Spirometry in primary care practice: the importance of quality assurance and the impact of spirometry workshops. Chest 1999;116:416-23. http://dx.doi.org/10.1378/chest.116.2.416

19. Soriano JB, Miravitlles M, Garcia-Rio F, et al. Spirometrically-defined restrictive ventilator defect: population variability and individual determinants. Prim Care Respir J 2012;21(2):187-93. http://dx.doi.org/10.4104/pcrj.2012.00027

20. Carr R, Telford W, Waters $G$. Impact of an educational intervention on the quality of spirometry performance in a general practice: an audit. Prim Care Respir $J$ 2011;20(2):210-13. http://dx.doi.org/10.4104/pcrj.2011.00006

21. Centers for Disease Control and Prevention (CDC). Spirometry training program: what is the NIOSH-approved spirometry training course? Available from: http://www.cdc.gov/niosh/topics/spirometry/training.html (accessed 1 July 2011)

22. Hnizdo E, Yu L, Freyder L, Lefante J, Glindmeyer HW. Precision of longitudinal lung function measurements-monitoring and interpretation. Occup Environ Med 2005;62:695-701. http://dx.doi.org/10.1136/oem.2004.018424

23. Enright PL, Johnson LJ, Connett JE, et al. Spirometry in the Lung Health Study: 1. Methods and quality control. Am Rev Respir Dis 1991;143:1215-23.

24. Miller MR, Quanjer PH, Swanncy MP, Ruppel G, Enright PL. Interpreting lung function data using $80 \%$ predicted and fixed thresholds misclassifies more than $20 \%$ of patients. Chest 2011;139(1):52-9. http://dx.doi.org/10.1378/chest.10-0189

25. Enright PL, Vollmer WM, Lamprecht B, et al. Quality of spirometry tests performed by 9893 adults in 14 countries: the BOLD study. Respir Med 2011;105:1507-15. http://dx.doi.org/10.1016/j.rmed.2011.04.008

Available online at http://www.thepcrj.org 